\title{
APLIKASI MEDIA PEMBELAJARAN AKSARA SUNDA BERBASIS ANDROID
}

\author{
Arini Habibah ${ }^{1}$, Dian Nur Sholihaningtias ${ }^{2}$, Noor Komari Pratiwi ${ }^{3}$ \\ Informatika, Universitas Indraprasta PGRI ${ }^{1.2 .3}$ \\ arinihabibah8@gmail.com ${ }^{1}$, dian.tyash@gmail.com² , noorkomaripratiwi01@gmail.com ${ }^{3}$
}

Submitted October 3, 2019; Revised March 13, 2020; Accepted March 16, 2020

\begin{abstract}
Abstrak
Aksara Sunda adalah hasil karya ortografi masyarakat Sunda sejak sekitar abad 5 M yang lalu hingga saat ini. Namun, minimnya media yang menarik dan memotivasi untuk mempelajari aksara, baik cetak maupun elektronik, membuat aksara Sunda terancam punah. Perkembangan teknologi yang semakin pesat dan era digitalisasi seperti saat ini, sebagian besar masyarakat Indonesia memiliki smartphone dengan sistem operasi Android yang mudah dibawa ke mana saja. Android tidak hanya dijadikan sebagai alat komunikasi dan hiburan semata, tetapi juga menjadi salah satu metode yang dapat dikembangkan sebagai media pembelajaran yang dapat menyampaikan materi pembelajaran secara tekstual, audio, dan visual. Tujuan dalam penelitian ini adalah untuk merancang aplikasi media pembelajaran aksara Sunda yang mudah digunakan serta mengimplementasikan aplikasi media pembelajaran aksara Sunda berbasis Android agar bisa menarik minat masyarakat dalam mempelajari aksara Sunda. Metode yang digunakan untuk pengembangan aplikasi adalah MDLC (Multimedia Development Life Cycle) aplikasi multimedia dalam pendidikan yang terdiri atas 6 tahapan, antara lain: Concept, Design, Material Collecting, Assembly, Testing dan Distribution. Hasil yang didapat dari penelitian ini adalah aplikasi media pembelajaran aksara Sunda berbasis Android. Aplikasi telah diuji dengan alpha test dan hasil dari uji coba tersebut dapat disimpulkan bahwa masyarakat dapat dengan mudah mempelajari aksara Sunda dengan tampilan yang menarik karena aplikasi ini dilengkapi dengan audio cara pengucapan aksara Sunda.
\end{abstract}

Kata Kunci : Aksara Sunda, Android, MDLC

\begin{abstract}
The Sundanese script is the work of orthography of Sundanese people since around the 5th century AD until today. However, the lack of interesting and motivating media to learn scripts, both printed and electronic, makes the Sundanese script endangered. With the rapid development of technology and the era of digitalization as today, most Indonesian people have smartphones with Android operating systems that are easy to carry anywhere. Android is not only used as a communication and entertainment tool, but also as a method that can be developed as a learning medium that can convey learning material textually, and audio-visually. The purpose of this research is to design an easy-touse Sundanese script learning media application and to implement an Android-based Sundanese script learning media application so that the public is interested in learning Sundanese script. The method used for application development is MDLC (Multimedia Development Life Cycle) multimedia application in education which consists of 6 stages, including Concept, Design, Material Collecting, Assembly, Testing and Distribution. The result obtained from this study is the Android-based application of Sundanese script learning media. The application has been tested with alpha test and from the results of the test, it can be concluded that the public can easily learn the Sundanese script with an attractive appearance because this application is equipped with audio pronunciation of the Sundanese script.
\end{abstract}

Keywords: Sundanese script, Android, $M D L C$. 


\section{PENDAHULUAN}

Aksara Sunda adalah hasil karya ortografi masyarakat Sunda sejak sekitar abad 5 M yang lalu hingga saat ini [1]. Aksara Sunda sudah dinyatakan sebagai aksara asli yang dilindungi kelangsungannya dan wajib untuk dilestarikan sesuai Peraturan Daerah (Perda) provinsi Jawa Barat Nomor 5 tahun 2003 tentang Pemeliharaan Bahasa, Sastra dan Aksara Daerah. Pada tahun 2008, aksara Sunda telah mengalami standardisasi dan modifikasi mutakhir. Aksara Sunda standar tersebut telah didaftarkan kepada Konsorsium International Unicode sehingga saat ini telah memiliki slot karakter khusus pada tabel sistem komputerisasi aksara dunia.

Di tengah perkembangan teknologi yang semakin pesat dan era digitalisasi seperti saat ini, sebagian besar masyarakat Indonesia memiliki smartphone dengan sistem operasi Android. Aplikasi mobile merupakan aplikasi yang dapat digunakan walaupun pengguna berpindah dengan mudah dari satu tempat ke tempat lain tanpa terjadi pemutusan atau terputusnya komunikasi [2]. Tidak hanya dijadikan sebagai alat komunikasi dan hiburan semata, tetapi Android juga menjadi salah satu metode yang dapat dikembangkan sebagai media pembelajaran yang dapat menyampaikan materi pembelajaran secara tekstual, audio, dan visual.

Media pembelajaran merupakan alat dan bahan yang digunakan untuk mengefektifkan dan mengefisienkan proses pembelajaran untuk mencapai tujuan pembelajaran [3].

Oleh karena itu, untuk menarik minat masyarakat mempelajari aksara Sunda, ditambah dengan peluang yang ditawarkan oleh Android, penulis merancang sebuah aplikasi media pembelajaran aksara Sunda berbasis Android.

Penelitian yang dilakukan oleh Dadan Nugraha dan Wisnu Ahmad Maulana pada tahun 2015 dari sistem informasi Universitas Kuningan, telah menghasilkan Rancangan Bangun Pengembangan Aplikasi Pembelajaran aksara Sunda untuk Madrasah Ibtidaiyah Berbasis Multimedia [4]. Software yang digunakan adalah Adobe Flash CS3 yang merupakan aplikasi standar authoring professional yang digunakan untuk membuat animasi dan bitmap untuk keperluan situs web yang interakaktif dan dinamis. Di dalam aplikasi ini terdapat animasi, teks, suara, simulasi dan evaluasi berupa kuis. Namun aplikasi ini hanya bisa diakses menggunakan komputer atau laptop. Referensi lain dari penelitian Rita Sri Ernawati, Eka Wahyu Hidayat dan Alam Rahmatulloh tahun 2017 dari teknik informatika Universitas Siliwangi telah menghasilkan Implementasi Teknologi Augmented Reality Sebagai Media Pengenalan Aksara Sunda Berbasis Android [5]. Hasil dari penelitian ini bertujuan untuk melesarikan aksara Sunda dengan mengenalkan huruf aksara Sunda dan terjemahan ke dalam bahasa latin dengan menerapkan teknologi Augmented Reality. Di dalam aplikasi ini selain menggunakan pemodelan 3D juga terdapat pemodelan 2D, tetapi tidak terdapat evaluasi berupa kuis di dalamnya. Adapun perbedaan dari masing-masing penelitian terdapat dalam tabel berikut.

Tabel 1. Hasil Penelitian

\begin{tabular}{|c|c|c|c|}
\hline No & $\begin{array}{l}\text { Aplikasi Media } \\
\text { Pembelajaran } \\
\text { Aksara Sunda } \\
\text { Berbasis } \\
\text { Android }\end{array}$ & $\begin{array}{l}\text { Rancang } \\
\text { Bangun } \\
\text { Pengembangan } \\
\text { Aplikasi } \\
\text { Pembelajaran } \\
\text { Aksaara Sunda } \\
\text { Untuk } \\
\text { Madrasah } \\
\text { Ibtidaiyah } \\
\text { Berbasis } \\
\text { Multimedia }\end{array}$ & $\begin{array}{l}\text { Implementasi } \\
\text { Teknologi } \\
\text { Augmented } \\
\text { Reality } \\
\text { Sebagai } \\
\text { Media } \\
\text { Pengenalan } \\
\text { Aksara } \\
\text { Sunda } \\
\text { Berbasis } \\
\text { Android }\end{array}$ \\
\hline 1. & $\begin{array}{l}\text { Evaluasi berupa } \\
\text { latihan soal } \\
\text { pilihan ganda }\end{array}$ & $\begin{array}{l}\text { Evaluasi tebak } \\
\text { aksara dan } \\
\text { menjodohkan } \\
\text { aksara }\end{array}$ & $\begin{array}{l}\text { Tidak terdapat } \\
\text { evaluasi }\end{array}$ \\
\hline 2. & $\begin{array}{l}\text { Dapat diakses } \\
\text { menggunakan } \\
\text { handphone } \\
\text { Android }\end{array}$ & $\begin{array}{l}\text { Diakses } \\
\text { menggunakan } \\
\text { computer atau } \\
\text { laptop }\end{array}$ & $\begin{array}{l}\text { Dapat diakses } \\
\text { menggunakan } \\
\text { handphone } \\
\text { Android }\end{array}$ \\
\hline
\end{tabular}




\begin{tabular}{|c|l|l|l|}
\hline 3. & $\begin{array}{l}\text { Terdapat audio } \\
\text { cara membaca } \\
\text { aksara dan } \\
\text { penjelasan } \\
\text { audio tanda } \\
\text { vokalisasi } \\
\text { aksara }\end{array}$ & $\begin{array}{l}\text { Terdapat audio } \\
\text { cara membaca } \\
\text { perubahan } \\
\text { bunyi aksara }\end{array}$ & $\begin{array}{l}\text { Tidak terdapat } \\
\text { audio }\end{array}$ \\
\hline 4. & $\begin{array}{l}\text { Tampilan untuk } \\
\text { umum dibuat } \\
\text { sederhana } \\
\text { dengan } \\
\text { permainan } \\
\text { warna dan tata } \\
\text { letak yan tepat }\end{array}$ & $\begin{array}{l}\text { Tampilan untuk } \\
\text { anak-anak dan } \\
\text { terdapat animasi }\end{array}$ & $\begin{array}{l}\text { Menggunakan } \\
\text { tampilan 3D }\end{array}$ \\
\hline \multicolumn{3}{|c|}{} \\
\hline
\end{tabular}

\section{METODE PENELITIAN}

Metode pengumpulan data yang dilakukan oleh penulis untuk mendapatkan data-data serta informasi untuk mendukung penyempurnaan hasil dari penelitian yaitu dengan studi kepustakaan. Selain itu, juga melalui mesin pencari di internet. Penulis mempelajari, menyimak dan mengambil simpulan dari data dan informasi melalui pustaka yang berkaitan dengan permasalahan yang dibahas.

Metode yang digunakan untuk pengembangan aplikasi adalah MDLC (Multimedia Development Life Cycle). Aplikasi multimedia dalam pendidikan terdiri atas 6 tahapan, antara lain: Concept, Design, Material Collecting, Assembly, Testing dan Distribution [7].

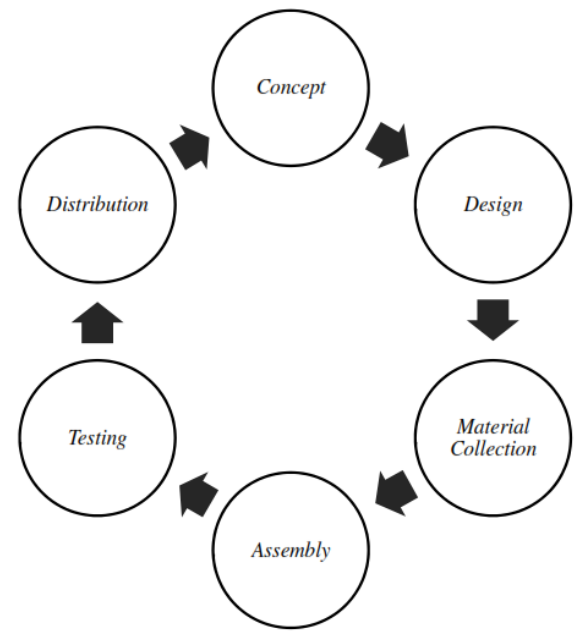

Sumber : Penulis

Gambar 1. Metode Multimedia Development Life Cycle

\section{Concept}

Tahap concept (konsep) adalah tahap untuk menentukan tujuan dan siapa pengguna program (identifikasi audience), macam aplikasi, tujuan aplikasi dan spesifikasi umum.

\section{Design}

Design (perancangan) adalah tahap membuat spesifikasi rinci mengenai arsitektur program, tampilan, dan kebutuhan material /bahan untuk aplikasi aksara Sunda. Dalam hal ini mulai merancang tampilan dari aplikasi baik itu perancangan isi dan perancangan naskah.

\section{Material Collecting}

Material Collecting adalah tahap pengumpulan bahan yang sesuai dengan kebutuhan yang dikerjakan. Bahan-bahan tersebut antara lain gambar, audio, animasi, dll. Tahap ini dapat dikerjakan bersamaan dengan tahap Assembly.

\section{Assembly}

Assembly (pembuatan) adalah tahap semua objek atau bahan dibuat. Pembuatan aplikasi di dasarkan pada tahap design.

\section{Testing}

Testing dilakukan setelah tahap pembuatan selesai, dengan menjalankan aplikasi dan melihat apakah ada kesalah atau tidak. Tahap ini disebut juga sebagai tahap pengujian alpha (alpha test) dimana pengujian dilakukan oleh pembuat atau lingkungan pembuatnya sendiri.

\section{Distribution}

Tahap aplikasi disimpan dalam suatu media penyimpanan. Tahap ini juga disebut tahap evaluasi untuk pengembangan aplikasi yang sudah jadi agar lebih baik. Hasil evaluasi ini dapat digunakan sebagai masukan untuk tahap concept pada produk selanjutnya

\section{HASIL DAN PEMBAHASAN}

Aplikasi aksara Sunda ini adalah salah satu media pembelajaran aksara Sunda dasar untuk kebutuhan edukasi atau pengetahuan 
budaya. Di dalam aplikasi terdapat penjelasan mengenai aksara Sunda, terdapat materi jenis-jenis aksara yaitu aksara swara (huruf vokal), aksara ngalagena (huruf konsonan), aksara angka, rarangkeun (tanda vokalisasi) dengan cara pengucapan serta penulisannya, serta berisi game pilihan ganda mengenai materi aksara yang sudah dipelajari oleh user. Seperti menjawab ujian, user hanya perlu mengklik salah satu jawaban dari setiap soal. Setelah menye-lesaikan game, user akan mendapat score nilai dari hasil total jawaban yang benar.

Adapun algoritma yang harus dipahami/ susunan langkah penyelesaian pembuatan program [8] menggunakan flowchart. Flowchart adalah repsentasi dalam bentuk diagram dari pemecahan sebuah masalah atau algoritma yang statefull [9].

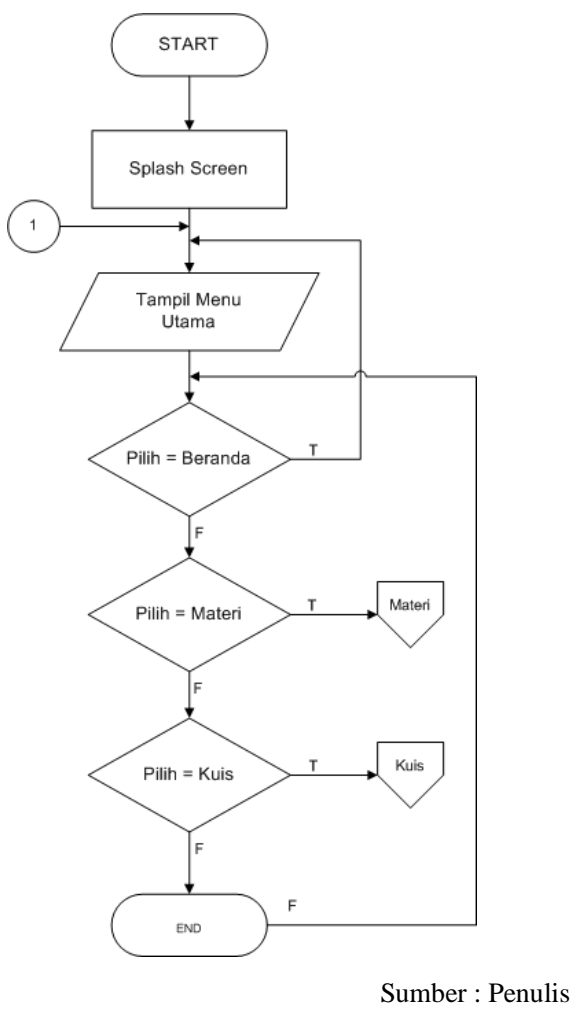

Gambar 2. Flowchart Aplikasi Aksara Sunda

Alur program pada gambar 2 merupakan menu utama dari aplikasi aksara Sunda, selajutnya dipecah menjadi beberapa flowchart menu.

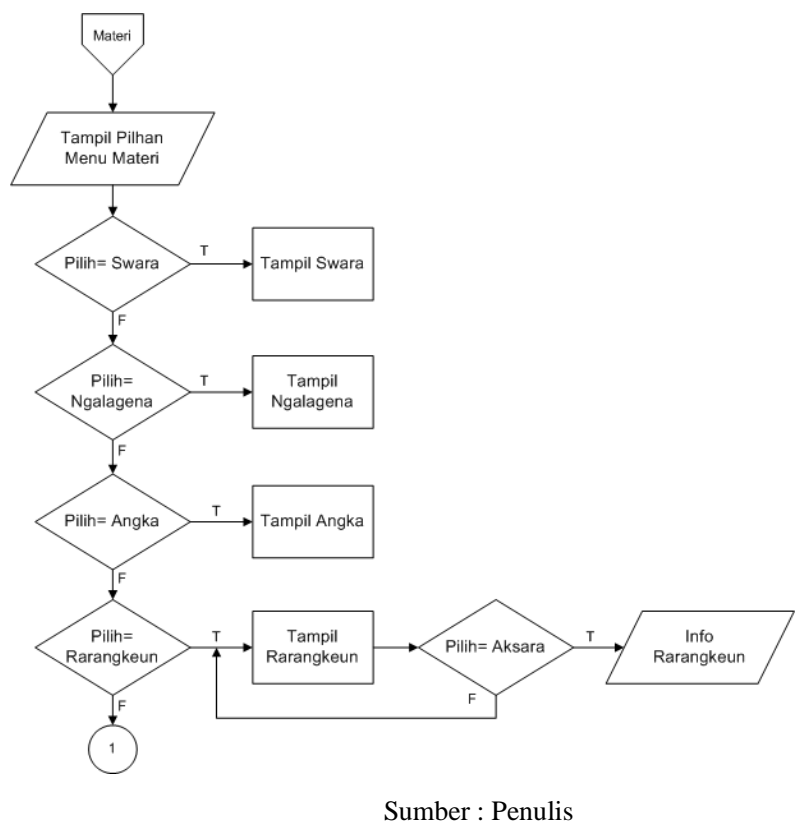

\section{Gambar 3. Flowchart Menu Materi}

Setelah masuk ke menu utama dan user memilih menu Materi, akan menampilkan halaman Materi dimana terdapat 4 pilihan materi aksara yang bisa dipelajari, yaitu materi aksara swara (huruf vokal), materi aksara ngalagena (huruf konsonan), materi aksara angka, dan materi rarangkeun (tanda vokalisasi). Yang mana apabila salah satu materi aksara tersebut dipilih akan menampilkan penjelasan, bentuk huruf dan cara pengucapan dari masingmasing aksara. 


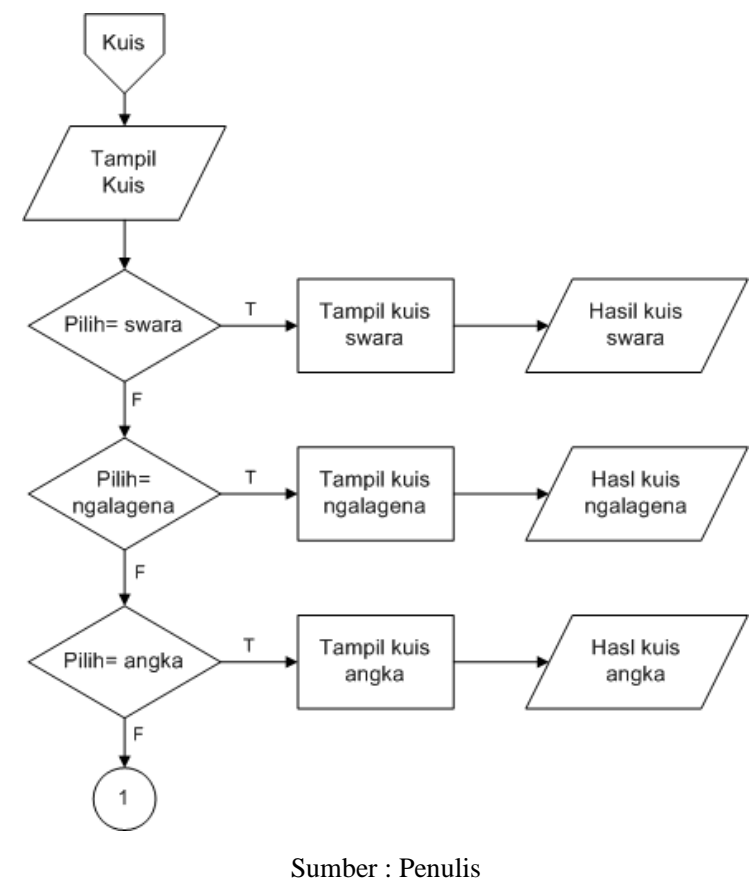

Gambar 4. Flowchart Menu Kuis

Setelah masuk ke menu utama dan user memilih menu Kuis, akan menampilkan halaman Kuis dimana terdapat 3 pilihan kuis aksara yang bisa dikerjakan, yaitu kuis aksara swara (huruf vokal), kuis aksara ngalagena (huruf konsonan), dan kuis aksara angka. Setelah user selesai mengerjakan akan langsung ditampilkan jumlah nilai score tertinggi dari kuis yang sudah dikerjakan sebelumnya dan hasil score saat ini.

Peneliti mulai persiapan pembuatan aplikasi terdiri dari beberapa langkah. Setelah menentukan konsep yang akan dibuat, mendesain rancangan layar, peneliti juga mengumpulkan bahan-bahan yang sesuai kebutuhan antara lain gambar, audio, dll. Pembuatan gambar dibuat menggunakan software Adobe Photoshop yang dikhususkan untuk pengeditan foto/gambar dan pembuatan efek [10] dan perekaman audio dibuat menggunakan software Audacity menggunakan microphone.

Proses pembuatan aplikasi Android aksara Sunda ini memerlukan perangkat pendukung berupa hardware dan software.
Perangkat keras (hardware) yang digunkaan adalah laptop dengan spesifikasi minimal processor Intel core i3, HDD 500GB, RAM 8 GB, mouse, keyboard, dan microphone. Perangkat lunak (software) yang digunakan dalam pembuatan aplikasi ini diantaranya: Android Studio, NoxPlayer, Adobe Photoshop, Audacity.

Uji coba aplikasi Android aksara Sunda dapat dilakukan.menggunakan laptop melalui emulator Android yaitu NoxPlayer atau melalui handphone dengan sistem operasi Android minimal versi Android 5.1 (Lolipop).

Hasil implementasi akhir aplikasi media pembelajaran aksara Sunda berbasis Android adalah sebagai berikut:

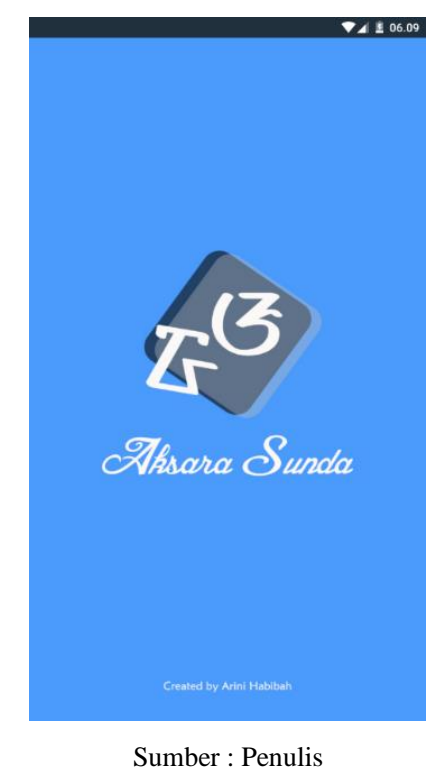

\section{Gambar 5. Tampilan Splash Screen}

Pada gambar 5 adalah tampilan awal pada saat pertama kali aplikasi ini dijalankan. Ini adalah tampilan loading dimana pada saat tampilan ini muncul maka aplikasi sedang menyiapkan data untuk masuk ke proses selanjutnya. 


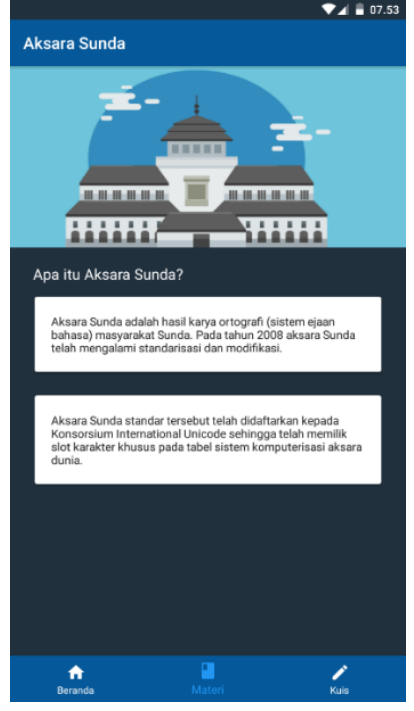

Sumber : Penulis

\section{Gambar 6. Tampilan Menu Beranda}

Pada gambar 6 adalah tampilan awal atau beranda dari aplikasi yang di dalamnya terdapat informasi mengenai aksara Sunda.

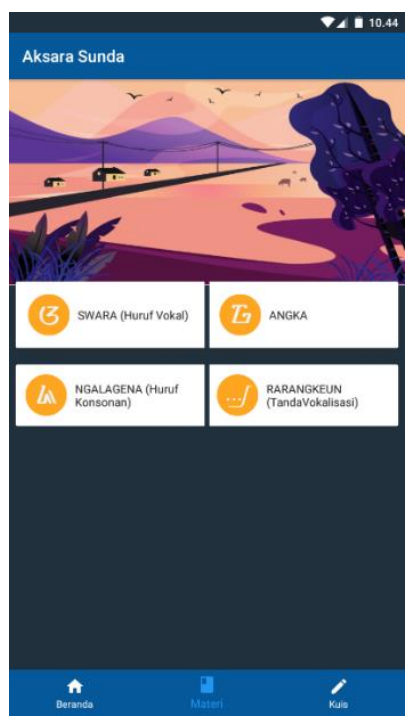

Sumber : Penulis

\section{Gambar 7. Tampilan Menu Materi}

Pada gambar 7 adalah tampilan menu materi yang di dalamnya terdapat empat submenu yaitu: button swara menuju halaman materi swara, button ngalagena menuju halaman materi ngalagena, button angka menuju halaman materi angka, dan button rarangkeun menuju halaman materi rarangkeun.

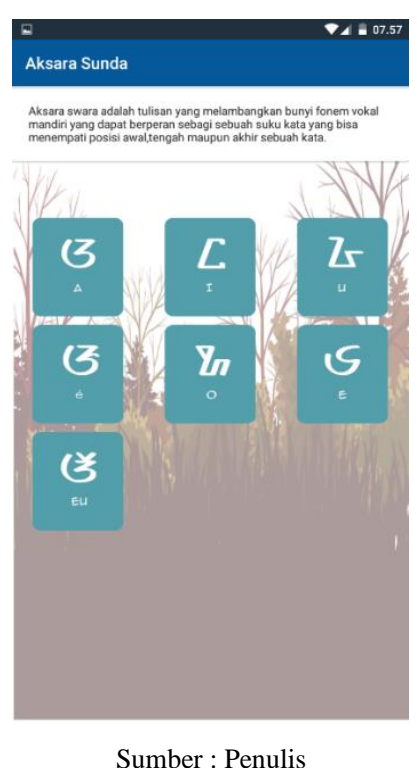

\section{Gambar 8. Tampilan Isi Submenu Materi Swara}

Pada gambar 8 adalah tampilan dari isi submenu materi swara yang di dalamnya terdapat 7 button yang apabila di klik akan mengeluarkan suara cara membaca huruf aksara sesuai dengan button yang dipilih.

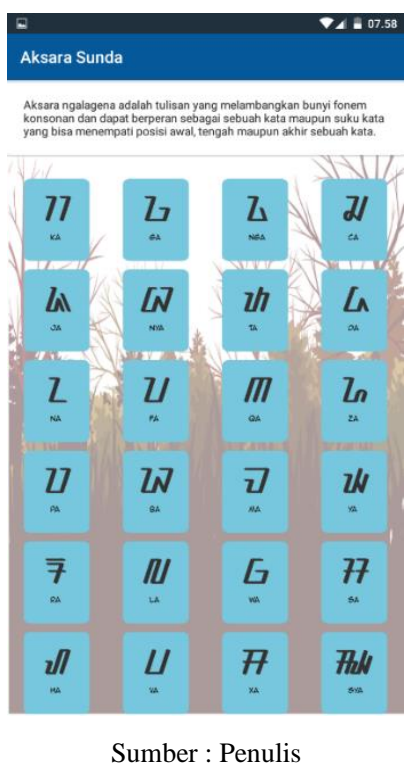

\section{Gambar 9. Tampilan Isi Submenu Materi Ngalagena}

Pada gambar 9 adalah tampilan dari isi submenu materi ngalagena yang di dalamnya terdapat 25 button yang apabila di klik akan mengeluarkan suara cara 
membaca huruf aksara sesuai dengan button yang dipilih.

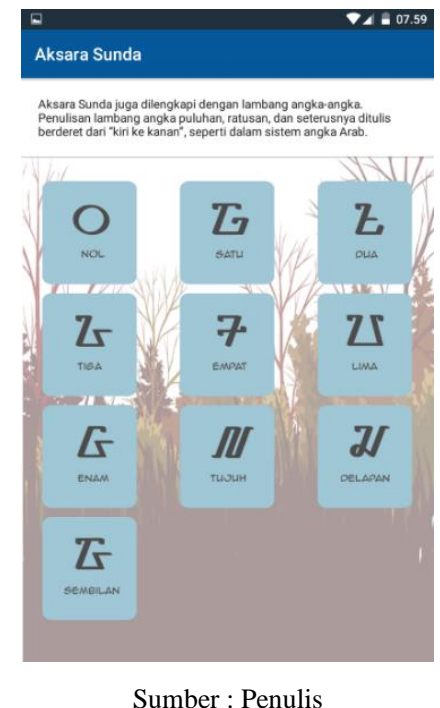

\section{Gambar 10. Tampilan Isi Submenu Materi Angka}

Pada gambar 10 adalah tampilan dari isi submenu materi angka yang di dalamnya terdapat 10 button yang apabila di klik akan mengeluarkan suara cara membaca huruf aksara sesuai dengan button yang dipilih.

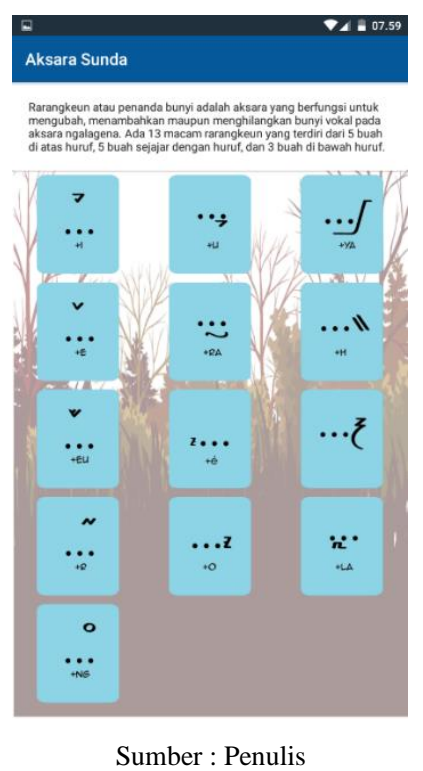

\section{Gambar 11. Tampilan Isi Submenu Materi Ngalagena}

Pada gambar 11 adalah tampilan dari isi submenu materi rarangkeun yang di dalamnya terdapat 13 button yang apabila di klik akan muncul popup seperti di gambar 12 berupa informasi cara penggunaan dan fungsi dari rarangkeun sesuai dengan button yang dipilih.

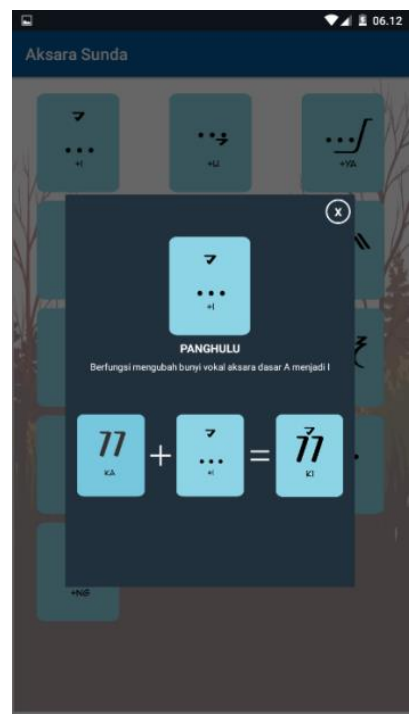

Sumber : Penulis

Gambar 12. Tampilan Popup Ngalagena

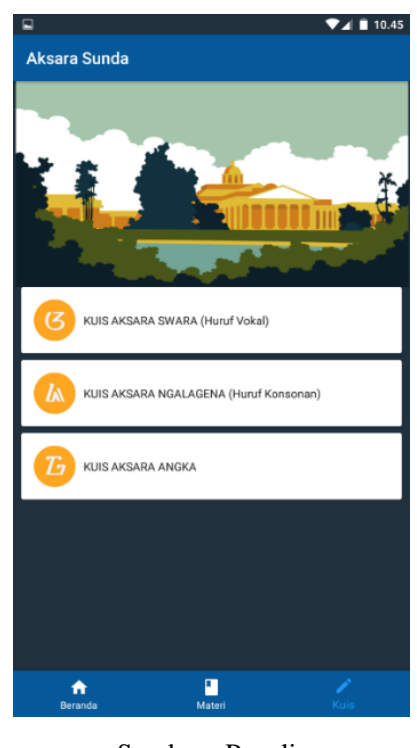

Sumber : Penulis

\section{Gambar 13. Tampilan Menu Kuis}

Pada gambar 13 adalah tampilan menu kuis yang di dalamnya terdapat 3 submenu yaitu: button kuis swara menuju halaman kuis swara, button kuis ngalagena menuju halaman kuis ngalagena, button kuis angka menuju halaman kuis angka. 


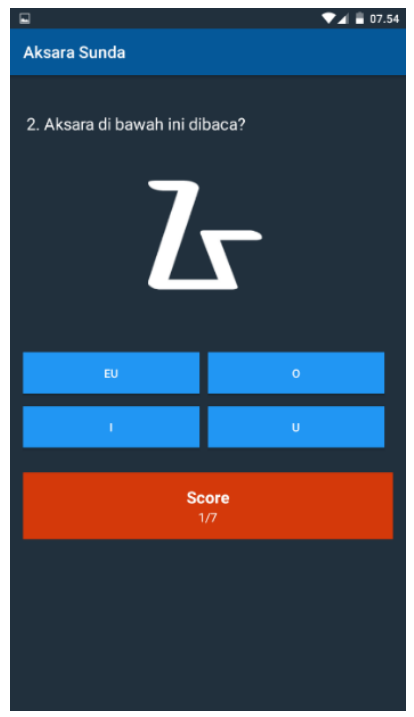

Sumber : Penulis

\section{Gambar 14. Tampilan Kuis}

Pada gambar 14 adalah tampilan kuis yang di dalamnya terdapat soal pilihan ganda dengan 4 opsi pilihan jawaban. Apabila jawaban yang dipilih benar maka skor akan bertambah.

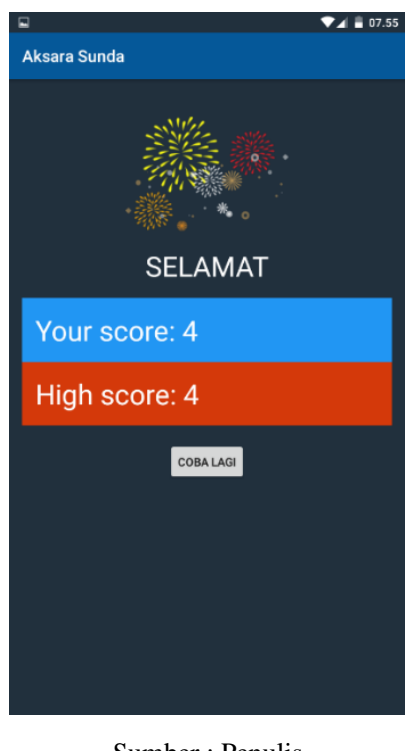

\section{Gambar 15. Tampilan Hasil Kuis}

Pada gambar 15 adalah tampilan kuis yang di dalamnya terdapat skor yang didapat setelah mengerjakan kuis dan skor tertingi yang pernah didapat setelah melakukan percobaan ulang kuis sebelumnya.

Tahap akhir dari perancangan sebuah aplikasi aksara Sunda berbasis Android adalah pengujian terhadap aplikasi itu sendiri. Pengujian yang dilakukan terhadap aplikasi yaitu dengan alpha test yang dilakukan oleh peneliti sendiri dan user yang melakukan test dalam metode ini sejumlah 15 orang dari berbagai elemen masyarakat.

Dari hasil pengujian, 14 orang mengakui baru pertama kali mengetahui mengenai aksara Sunda. Responden merespon positif terhadap aplikasi, terutama dengan tampilan aplikasi, informasi yang disajikan mudah dimengerti, sehingga membantu dalam memahami aksara Sunda itu sendiri.

Dalam sebuah aplikasi tentu ada kelebihan dan kekurangan begitu juga aplikasi aksara Sunda berbasis Android.

1) Kelebihan Aplikasi

a. Aplikasi aksara Sunda ini mudah digunakan, kapan pun dan di mana pun karena bisa diakses melalui smartphone.

b. Penjelasan yang singkat dan dilengkapi dengan gambar serta suara membuat aplikasi ini mudah dipahami dan tidak cepat bosan saat mempelajarinya.

c. Terdapat kuis untuk menguji pamahaman user terhadap materi yang diberikan.

2) Kekurangan Aplikasi

a. Aplikasi ini hanya dapat digunakan pada perangkat yang menggunakan sistem Android.

b. Tidak terdapat contoh penulisan kalimat menggunakan aksara Sunda.

c. Tidak terdapat video cara penulisan aksara.

\section{SIMPULAN}

Berdasarkan hasil penelitian dan pembahasan, dapat disimpulkan bahwa pembuatan aplikasi media pembelajaran aksara Sunda dimulai dengan menentukan audience, dilanjutkan pembuatan flowchart dan pseudocode, perancangan design 
layout, pembuatan bahan yang diperlukan seperti audio, gambar. Kemudian dilakukan pengkodean dengan bahasa pemrograman Java yang berbasis Android. Aplikasi aksara Sunda ini ditentukan dengan minimal Android Software Development Kit (SDK) Android 5.0 (Lollipop) ke atas. Untuk mempermudah user dalam mempelajari aksara Sunda, aplikasi aksara Sunda berbasis Android ini dilengkapi dengan audio cara pengucapan akasara dan berisi penjelasan yang singkat namun mudah dimengerti disetiap materinya. Desain tampilan yang sederhana dengan gambar-gambar ilustrasi yang meng-gambarkan ciri khas beberapa kota di Jawa Barat dan penggunaan warna yang sesuai membuat aplikasi ini menarik dan tidak mudah bosan saat mempelajari aksara Sunda.

Untuk pengembangan lebih lanjut terhadap aplikasi aksara Sunda ini, peneliti menyarankan beberapa hal yaitu:

1) Smartphone yang user gunakan minimal meggunakan sistem android 5.0 (Lollipop).

2) Tambahkan penerjemah tulisan latin yang bisa dikonversikan ke aksara Sunda.

3) Untuk mempraktikkan penulisan aksara Sunda bisa ditambahkan video cara penulisan aksara dan latihan penulisan aksara.

4) Perbanyak contoh penulisan kalimat dalam aksara Sunda.

\section{DAFTAR PUSTAKA}

[1] Mulyono, Aksara Sunda Baku. Bandung: Kiblat Buku Utama, 2012.

[2] N. Safaat, Android Pemrograman Aplikasi Mobile Smartphone dan Tablet PC Berbasis Android. Bandung: Informatika, 2014.

[3] Satrianawati, Media dan Sumber Belajar. Yogyakarta: Deepublish, 2018.

[4] D. dan W. A. M. Nugraha, "Rancangan Bangun Pengembangan Aplikasi Pembelajaran Aksara Sunda Untuk Madrasah Ibtidaiyah Berbasis Multimedia," Cloud Inf., vol. 1, 2015.

[5] Rita Sri Ernawati, Eka Wahyu Hidayat ,dan Rahmatulloh Alam, "Implementasi Teknologi Augmented Reality Sebagai Media Pengenalan Aksara Sunda Berbasis Android," Tek. Inform. dan Sist. Inf., vol. 3 nomor 3, 2017.

[6] R. K. Widi, Menggelorakan Penelitian; Pengenalan dan Penuntun Pelaksanaan Penelitian. Yogyakarta: Deepublish, 2018.

[7] A. H. Sutopo, Teknologi Informasi dan Komunikasi dalam Pendidikan. Yogyakarta: Graha Ilmu, 2012.

[8] L. Sitorus, Algoritma dan Pemprograman. Yogyakarta: Andi Offset, 2015.

[9] R. dkk Syaifudin, Dasar Pemrograman. Malang: Polinema Press, 2018.

[10] G. Putu, Media dan Multimedia Pembelajaran. Yogyakarta: Deepublish, 2017. 